\title{
'I'm Not Just a Housewife': Gendered Roles and Identities in the Home-Based Hospitality Enterprise
}

\author{
MariaLaura Di Domenico
}

This article was published in the journal Gender, Work and Organization (2008) vol.

15, issue 4, pp. 313-332.

DOI: http://dx.doi.org/10.1111/j.1468-0432.2007.00388.x

\section{Author's Details:}

Dr. MariaLaura Di Domenico

Reader in Organisational Behaviour,

Surrey Business School, University of Surrey

Guildford GU2 7XH, United Kingdom 


\title{
'I'm Not Just a Housewife': Gendered Roles and Identities in the Home-Based Hospitality Enterprise
}

\author{
MariaLaura Di Domenico
}

\begin{abstract}
This article explores an under-researched form of commercial hospitality provision by analysing the gender dynamics in the distinctive occupational setting of the home. The primary contribution is to extend understanding of traditionally female occupations by adding to accounts in the literature on gendered identities and occupational roles in small and micro enterprises. It is based on in-depth interview findings from 33 home-based commercial hospitality proprietors in Scotland. These enterprises perform the twin functions of private home and providing revenuegenerating, short-term accommodation. The findings reveal three broad categories of proprietor; the female sole proprietor, proprietor couples and the male sole proprietor, all of whom reinforce traditional gender-based roles and stereotypes. As an extension of domestic labour, commercial 'home hosting' is inherently gendered. It is argued that this is very pronounced in home-based commercial hospitality where home and business spheres overlap.
\end{abstract}

Keywords: gendered occupation, home-based business, micro enterprise

\section{Introduction}

Guesthouses and bed and breakfasts are ubiquitous types of small businesses found throughout the UK, representing approximately one-quarter of available tourist accommodation. ${ }^{1}$ Despite this, there is a dearth of research focusing on home-based businesses and the domestic context of self-employment in commercial hospitality. The focus of this article is on the integration of commercial hospitality provision in the traditional functions of the home. It outlines, through an analysis of their interview accounts, the gendered roles and identities of male and female guesthouse proprietors in Scotland. All have to negotiate the simultaneous demands of paid and unpaid 
domestic labour in a spatial setting with overlapping boundaries, functions and users. In this analysis the role of the proprietor in the commercial home setting provides a gendered frame for identity and interaction in this private, individualized work environment. Like other occupational roles in the broader hospitality sector where most labour is demarcated by gender (Guerrier and Adib, 2000; Lucas, 1995; Wood, 1992), these business owners, as commercial home 'hosts' (Stringer, 1981), serve paying guests. However, this role is carried out in the domestic domain, a private and traditionally feminized space (Madigan and Munro, 1996), rather than in the capacity of 'employee' in a large-scale organization.

By focusing on the home-based hospitality enterprise, this article extends existing understandings of traditionally female occupations and accounts in the literature of gendered occupational roles in small and micro enterprises (Baines and Wheelock, 1998; Smith, 2000). It contributes to an understanding of the importance of gender in the negotiation of occupational identity and role configuration where there is a blurring of spatial and temporal differentiation between home and work contexts.

The article has two core objectives. The first is to ascertain the processes by which proprietors socially construct their own occupational roles and identities in home-based commercial hospitality. This involves an elucidation of role designation and labour divisions between the host and other family members. It helps to determine how the home-work interface is managed, and to address the issue of the significance of gender to the commercial home proprietors' occupational definitions. Thus, the focus on the interaction and boundaries between the business and home spheres is interwoven throughout the analysis, thereby taking into account the location-specific nature of this form of work as being bound by the domestic context.

The second objective is to determine the gender-based identities, stereotypes and coping strategies of male hosts as compared with those of their female counterparts. This linked critique of male reactions and coping strategies emerged inductively during data collection and analysis and was not originally put forward as a theme for investigation. However, the findings relating to this issue led to insights into the gendered constructions held by both men and women. These add to existing evidence on the views and experiences of men in female-dominated occupations (Cross and Bagilhole, 2002; Lupton, 2000; Simpson, 2004, 2005; Williams, 1995).

The remainder of the article is divided into four parts. Firstly, the context is set by a review of the literature relevant to gender and home-based commercial 
hospitality. Secondly, the method and approach framing the empirical research design and analysis is outlined. This is followed by the presentation of findings in the third section, which is structured by an exploration of two core issues; role specialization and boundary maintenance at the home-work interface, and gender based stereotypes and coping strategies. In the concluding section, the implications of these findings for existing research are discussed. This includes reflection upon the need for giving increased attention to diverse modes of income generation, such as home-based micro enterprises where there is a convergence of home and business spheres.

\section{Gender and home-based commercial hospitality}

There is a large multi-disciplinary literature on the meaning and purpose of the private home (for a review see Mallett, 2004). Rybczynski (1988) contrasts gendered conceptions of the home from the early 1900s, showing how the masculine idea of the home was primarily one of retreat and ease, while the feminine idea combined work with ease. Despite a masculinized notion of the home as residential in purpose and distinct from the workplace, historically the boundaries between home and work have been blurred, especially for women. Attempts to distinguish between the home domain and work space are linked to changes caused by industrialization, prior to which there was a less clear-cut separation of places for living and spaces for generating income. This separation of income-generating activities performed in public spaces away from the home domain resulted in domestic labour becoming privatized and demeaned (Lorber, 1994). Thus, public and private spaces became differentiated and defined increasingly in gendered terms, with the former seen as inherently masculine and the latter as feminine. This paved the way for modern forms of labour organization based upon assumptions of the separation between work and home spaces and activities (Whitehead, 2002). In their study of various micro businesses in the service sector, Baines and Wheelock (2000, p. 45) argue that such businesses reflect a return to traditional ways of organizing whereby there is a 'reproduction within modernity of seemingly pre-modern practices in household organization and gender divisions of labour'. Home-based hospitality businesses which integrate the business and household spheres dissolve these home-work boundaries, while continually reforming and reshaping these domains to suit the needs of their occupants. 
Due to gendered public and private distinctions women are often encountered in politically contested and negotiated public spaces as gendered others. This has consequences for the kinds of femininity they express and experience (Rainsborough, 2002). In contrast, the home is a largely feminized environment where women are expected to act out their femininity. The home's everyday spaces reflect inescapable, external sociocultural norms and socially approved constructions of femininity that are closely associated with notions of care-giving and nurture. By running homebased hospitality enterprises female hosts remain within this setting, while challenging their gendered stereotypes of voluntary, unremunerated care-giving. Male hosts also challenge gendered stereotypes by remaining attached to the domestic sphere.

Micro enterprises, particularly home-based businesses, may allow the combination of work-production and home-consumption domains. Community-based business start-up schemes have encouraged such domestic enterprises, which are often linked through socio-political rhetoric to women's socioeconomic concerns. Ehlers and Main (1998) criticize these approaches, arguing that gender-based choices keep women outside the mainstream business world, economically vulnerable and socially peripheral. Women typically run 'small-scale, undercapitalized, and barely profitable "pink-collar" businesses, largely home-based operations based on work women are already doing as part of their gender-specific role' (Ehlers and Main, 1998, p. 424). Moreover, rather than portraying a straightforward merger of work-related and domestic activities, home-based businesses present the challenge of effective boundary maintenance and relationship co-ordination, with times and spaces juggled amongst functions (Felstead and Jewson, 2000; Phizacklea and Wolkowitz, 1995). The home-based hospitality enterprise involves interactions and overlapping times and spaces of both paid and unpaid work, and leisure. Time and space are key organizing mechanisms that are central to identity and the organization of social roles (Giddens, 1979). The research outlined in this article addresses the need for a greater understanding of the conceptualizations of commercial domestic hospitality space in the home, when its raison d'être and economic viability have been explicitly altered to encompass economic enterprise.

Using a dramaturgical perspective, Goffman (1959) explores the constraints imposed on the individual of occupational roles in the service sector, using examples of front/back stage behaviour patterns of waiters in a small Shetland hotel. 
Comparisons can be made with the context of the small, home-based enterprise in terms of the ways that home-work and host-guest spatial boundaries are actively reinforced by those involved in the interaction. Other studies have drawn upon Goffman's thesis, analysing hospitality as performance and the consequent impression management implications enacted by the host (Darke and Gurney, 2000; Hochschild, 1983; MacCannell, 1973). However, important distinctions need to be drawn between different sites of commercial hospitality. Despite the fact that the product in both larger hotels and home-based hospitality enterprises is similar, size and the dominance of the spatial context of the home or business differentiates each type of business. Although the larger hotel can be conceptualized as containing domestic spaces with surrogate 'home away from home' guest experiences (Guerrier and Adib, 2000), home-based commercial hospitality does not mimic the home setting but takes place in the actual residences of the commercial hosts. This has a dynamic impact upon the way hosts choose to articulate boundaries between familial and more commercial space, as well as the way customers respond to that separation when entering someone else's domestic space.

In the service sector women predominate in occupations that reflect family roles and daily, unremunerated, domestic chores (Howe, 1977). This is evident in the hospitality industry, where much labour is segregated along gender lines (Guerrier and Adib, 2000; Lucas, 1995; Wood, 1992), and where roles involving cleaning and housekeeping are often demeaned through association with household divisions of labour. These differ from more skilled roles. For example, the chef can be defined as a creative culinary artist. As an everyday act housework tends to be socially ascribed as a part performed mainly by female actors (Leonard, 2001). Interesting parallels may be drawn with masculinized, manual, blue-collar industrial labour, also involving elements of routine tedium, repetition and ties to a particular space (Oakley, 1974). In the home, there is an explicit gendering of performance and societal roles. Housework, as unpaid domestic work, is attributed an inferior feminized status. This status is then transposed to the context of paid domestic work and associated activities, whether these are carried out in one's own home, as in the present research, or in someone else's home, as in the case of much paid domestic labour (Meagher, 1997; Moss, 1997), or for larger commercial entities (Adib and Guerrier, 2003). Thus housekeeping, a clearly gendered role, refers to low status rankings of employees in hotels and other service organization hierarchies. 
The complex and often contradictory identities held by the commercial home proprietors are compounded by their multiple roles, as they typically must fulfil all the various task requirements that would be designated to different staff members in larger hotels. Their role could be regarded as a paradoxical one as, unlike many other typically underpaid, exploited service-sector roles that involve similar tasks (Brown and Crossman, 2000; Gray, 2004; Guerrier and Adib, 2000; Macaulay and Wood, 1992), these individuals have high levels of occupational autonomy and are typically homeowners. This raises questions about the prevailing constructions held by those working in the complexities of this hitherto largely neglected and ambivalent space. These individuals must negotiate the dual processes of household production and consumption, involving overlapping paid and unpaid work.

Thus hosting in the home and its usage for income generation is a logical extension of an existing worksite of unpaid domestic labour. Although such dualpurpose home-work spaces are traditionally female-dominated, with the inevitable associated imagery of landlady and lodging houses (Walton, 1978), the gendered performances associated with these spaces take on a new light when the actors are male. Men who run home-based hospitality enterprises can face acute dilemmas. The performance of masculinities acted out in the home domain contradicts dominant constructions of masculinity that this space traditionally allows (Whitehead, 2002). Previous research has examined the coping strategies adopted by men working in predominantly female occupations. These include roles such as nursing, primary school teaching, librarianship and flight-attending (Cross and Bagilhole, 2002; Lupton, 2000; Simpson, 2004, 2005; Williams, 1995), or those in the creative and professional service industries where the emotionally governed work itself holds many conventionally 'feminine' facets and where the workplace gender is dynamic and ambiguous (Alvesson, 1998).

The findings from the present research explore gendered performances and strategies of male, as well as female, proprietors of home-based hospitality enterprises. This is a significant addition to the broader analysis of gender-based identity constructions in the workplace. It also adds to the understanding of gendered roles and interactions in a female-dominated business sphere where the domestic context pervades (Lynch and MacWhannell, 2000; Stringer, 1981; Whatmore, 1991).

There are many different forms of home-based employment that combine domestic and income-generating activities (Hennon et al., 2000), a strategy 
predominantly used by women. There has been some research into the work-home interface when the workplace is also the home context. However, studies tend either to focus on white-collar home teleworking (Shumate and Fulk, 2004; Sullivan and Lewis, 2001; Wilson and Greenhill, 2004) or the employment of domestic labour for cleaning or childcare (Meagher, 1997; Moss, 1997). These represent two dominant literature strands which focus on the conflicting images of paid work at home. There is the image of high discretion white-collar work actively embraced by those selling their labour outcomes to clients. The opposing image is one of the low status, low discretion homeworking of those who receive low pay from their employers in exchange for manual labour carried out in their homes (Felstead et al., 2001; Felstead and Jewson, 1997). However, few examine the conversion of the home itself into a micro enterprise for the provision and consumption of commercial hospitality. In this scenario the home is part of the hospitality product being consumed by paying guests. With commercial home-based hospitality provision the proprietor exercises choice and enjoys autonomous self-employment and business ownership. However, the work involved is menial, repetitive and routine due to the service nature of the tasks and their domestic-sphere boundaries. Thus the complexities inherent in this type of work need elucidation as it does not appear to fit neatly into existing mainstream categories of home-working or the home-based enterprise. This research redresses this omission by examining the interplay between home and work spaces in home-based hospitality enterprises and the role that gender plays in their negotiation.

\section{Method and approach}

The research, using qualitative in-depth interviews, involved a comparative investigation into the views and self-definitions of hosts in home-based hospitality enterprises in two contrasting Scottish cities, tourist-historic Inverness and postindustrial Dundee. Guesthouses and bed and breakfasts were specifically chosen as excellent examples of home-based hospitality businesses. As no comprehensive database of such businesses existed, a sample frame was collated by combining local business listings with the tourist board's database of guesthouses and bed and breakfasts in these areas. Letters were sent to 106 guesthouses and bed and breakfasts identified as likely home-based businesses. These were followed by telephone calls to determine the proprietor's willingness to participate in the research. Of these, 55 agreed to take part in the research. However, 22 of these were excluded as they did 
not fulfil the criterion of being home-based. This left a final sample of 33 proprietors, 17 in Dundee and 16 in Inverness. Research interviews were held, with each taking approximately one and a half hours. Women made up the majority of participants, 23 of the total, reflecting the continued female dominance of this occupational grouping. All participants were aged between 40 and 69, a typical age profile in an occupational sector where the home ownership required tends to be linked to age. All the participants were found to be part of married or cohabiting couples. Six had children still residing at home, three had no children and the remaining participants had children who were resident away from home, mainly due to their age and life-stage. Fifteen were part of a 'copreneurial' couple (Smith, 2000), that is entrepreneurs running the business jointly with a spouse. Where the proprietor's spouse held fulltime paid employment outside the home, the participants defined their business ownership as sole proprietorship. Eighteen proprietors fell into this category, only two of whom were male business owners whose wives were in full-time work outside the home.

All the interviews were conducted in the business home location of the participants in order to place them in their natural setting. This also allowed the researcher a greater insight into the nature of their businesses. All the interviews were tape-recorded and later transcribed verbatim in order to facilitate analysis. Previous analyses of work in the hotel and hospitality sector have focused on issues such as low pay (Arrowsmith et al., 2003; Brown and Crossman, 2000; Gray, 2004; Macaulay and Wood, 1992) and race and ethnicity (Adib and Guerrier, 2003; Guerrier and Adib, 2000). However, these were not found to be key issues in this study due to the fact that the participants were self-employed homeowners who defined themselves as white Scottish/British.

Use of language is at the heart of the social categorizations of occupational roles and particular words, as labels, carry particular meanings (Davidoff, 1995). Traditional connotations of the word 'landlord' carry associations of a male owner of property who typically collects rent from tenants but is unlikely to occupy the same dwelling as them. In contrast, the notion of a 'landlady' is closely linked to the role of a commercial home proprietor, where the woman of the house lives on the premises and provides accommodation, food and other domestic services in return for payment (Walton, 1978). The notions of detachment, elevated status and ownership of property are far more explicit in the former case. In order to avoid imposing gendered 
conceptions, neutral language such as 'proprietor' or 'owner' was used during the interviews. Gender-laden terminology is used in this article only when taken from the participants' verbatim statements, reflecting their individual views and associations.

Respect for privacy was sensitively maintained and the names of the participants and businesses have been given pseudonyms to ensure confidentiality. The interviews of both female and male participants were analysed in-depth using framework analysis (Ritchie and Spencer, 1994). This method involves data reduction and interpretation by means of thematic coding and cross-case comparison. The key stages involved are data familiarization, the identification and application of thematic codes, the synthesis of coded text, and charting, and mapping and interpretation (Ritchie and Spencer, 1994). This method of substantive analysis thus involves classification, sorting and data reduction by labeling the transcribed data according to themes/categories and sub-categories that themselves emerge from an initial reading and familiarization with the text. The data are then sorted and grouped according to these categories in order to allow it to be summarized and synthesized. This process was facilitated by the use of MaxQDA (Verbi Software, Marburg, Germany), a qualitative analysis software package for data management, coding and retrieval.

The broad conceptual category of identity construction was found to be heavily gender laden. Further subcategories were devised to structure and group the data. The first of these dealt with role specialization and boundary maintenance. The second covered gender-based stereotypes and coping strategies. The findings in the following section are structured according to these two subcategories, which arose from the analysis and are now addressed in turn.

\section{Results}

Role specialization and boundary maintenance at the home-work interface

A key theme framing the analysis is the dual function of the enterprise for the owner as both a business and a home. In this context, the findings highlight the implications that definitions of their own situations and identities have for the proprietors, both in terms of their roles in their families and the development of their businesses. All research participants discussed at some length issues relating to family and occupational roles in the running of their businesses. Their views on their roles were heavily defined by gender. Occupational and family roles were explored in order to determine how these are negotiated between the proprietor and spouse or other family 
members. Some participants identified a high degree of role specialization, where roles were designated with defined divisions of labour. It was clear from the descriptions given that these roles were defined in terms of traditional gender-based labour division in the home domain:

She [host's wife] cooks the breakfasts and I serve them.... She makes the beds and cleans and tidies the place up. So we have our system of how to keep things going. I'm also the handyman as I do things like put pictures up and change light bulbs and all the necessities to keep the place going. (Man, copreneur)

My husband, well he's very interested in it. I know a lot of the other husbands just don't have anything to do with it. Yes, he's very supportive.... Well, mostly. He does a lot for the place, maintenance-wise, when he comes home. And my sister and daughter help out with things too. I know people along the road who only have three bedrooms and they find it really hard work. Well, I have eight bedrooms and I manage to cook breakfasts and everything... But I've always done breakfasts on my own. Jim might help if I've got a lot of visitors needing attention at the same time, but usually I do them on my own. (Woman, sole proprietor).

He's a maintenance man, a tradesman [reference to host's husband]. No. He's dreadful. He's more anti-social than I am [laughs]. If I'm out he won't even answer the door [interviewee emphasis]. He's dreadful [laughs]. But he keeps the place and everything in working order. (Woman, sole proprietor)

For all proprietor categories, other family members also sometimes assist in the business. Where children are part of the household and exposed to the business for any period of time their participation tends to develop into regular, expected, domestic duties as might be carried out in a private home: 'The kids just learnt to live with it. They carry out chores, and the older ones help me by running the place when we've been on holiday' (Woman, sole proprietor).

Despite gendered role constructions, both men and women used boundarymaintaining mechanisms to achieve a physical or emotional separation of home and business spaces. Male and female participants described the means that they 
employed to achieve separation between these two interconnecting spaces. For example, this could take the form of limiting guests' access to certain parts of the house by retaining a floor, or section of it, for sole use by host and family:

Just the one bedroom and this lounge ... reserved just for us... The guests are free to come and go, but you've also got your own private accommodation and you don't want them going through that to get to the door ... we just lock up this. So it works out quite well. The rest is left open.... They come in the front door and that's not alarmed. But if they come in the back door, that's alarmed. (Woman, copreneur)

Some specific times of day were also designated as being devoted to non-business concerns. These mechanisms were used to avoid potential problems that the participants had experienced when boundaries had not been set up between home and business. They were used deliberately to prevent tensions from the business being brought into the realms of home and family and vice versa. Inappropriately carrying over of activities could disrupt the dynamics of each. Indeed, although there was a competition for the resources of time and physical space, the host continuously sought an active separation of these domains through controlling definitions of norms and boundaries. Therefore, both the spatial and temporal organizing principles of achieving some degree of separation between business and home were in evidence, not only during interview encounters, when the proprietors would recount the way in which these boundaries would be devised, but also through researcher observations. The interviews were accompanied by a tour of the entire property, including guest bedrooms and dining areas and personal familial spaces. The more commercial spaces, such as the guest bedrooms, tended to be tidier, while the areas for the host and family contained all the normal facets of everyday living, such as laundry waiting to be ironed and groceries to be unpacked. In the cases of the six sole female proprietors, who had children still residing at home, books and children's toys were also evident and largely restricted to these private backstage areas. Although the interviews were conducted during less busy times of the day, occasional interruptions to interviews would take place where the host would answer the telephone to take a booking. The following interview excerpt illustrates such fragile spatial and temporal 
boundaries, as well as the dynamic everyday 'lived' nature of the home/business setting:

Excuse the mess. This room is just for us. You probably noticed with all the junk lying about [laughs].... We have a basement as well down the stairs and that's ours. Nobody comes in there at all. The door's locked.... You've got to have your own space. I come in here for half an hour or whatever for some time out. (Woman, sole proprietor)

Thus, the business is not merely a static stage but rather an active extension of the proprietor's home, where the presence of everyday features may provide reassurance and a sense of authenticity for the guest due to their familiarity. Such ambiguity represents a counterpoint to the larger hotel with clearly compartmentalized spaces. In the home-based hospitality enterprise there is a fluidity of boundaries, constantly dissolving and reforming according to the presence or absence of the customer:

[W] hen it's quieter I can slope downstairs in my nightie and I think, 'hold on I can go round with bare feet'... things you can't do [interviewee emphasis] when you've got people in the house and you're always having to look respectable. (Woman, sole proprietor).

Role conflict for the female sole proprietor was evident where their spouses engaged in alternative employment activities were perceived as being resentful of the demands of the business. This was not evident in the views of either copreneurial couples or male sole proprietors. The following interview excerpt illustrates the spouse's resentment as perceived by the female sole proprietor. In this case it was about business demands encroaching on leisure time. It shows the strategies employed by the female host to protect her husband from perceived intrusion arising from the guest's presence:

When people would come up for the weekend, they would phone up on a Friday night and my husband likes to go out on a Friday night, so I would say to them 'what time are you arriving?' and once or twice George has said 'oh, I'm fed up 
with this' ... and so for a little while I would never take anybody on a Friday night until he got over it again'. (Woman, sole proprietor)

This indicates the reinforcement of gender-based roles by female hosts as they attempt to separate the business and the home domain in order to manage, for example, aspects of the enterprise that they see as intruding upon the leisure-time of their working male partners. They also attempt to preserve the sanctity of the private home space as an area for rest and recuperation, a definition of which corresponds closely to the masculinized notion of the home space (Rybczynski, 1988). Male hosts with wives working outside the home do not shield them from its demands or intrusions in the same way. However, they still desire the separation of home and work spaces in order to preserve the distinctiveness of their private domestic space. This is used as a mechanism to protect their own, rather than their spouse's, personal time and space. This is reflected by the following extract:

Guests stay in the upstairs bit and we live downstairs ... my wife is a Scots law accountant ... and an absolutely excellent cook. She took bad to it [opening a guesthouse in the home]. She wasn't keen on it in the beginning but then I thought 'well, I've got to do something'. So she helps me at the weekend with things like the washing up. (Man, sole proprietor)

I try to keep our part of the house separate as much as I can so you can shut off when you need to and get a bit of respite. My wife's a theatre nurse at the hospital and sometimes works awkward shifts and gets home at all sorts of different times, sometimes even in the wee hours of the morning. I know it gets her down sometimes [reference to the guesthouse] as she calls it her 'second shift' but there's nothing I can really do about that. It's just the way things are. (Man, sole proprietor)

The way in which proprietors interact with customers in their negotiation of gendered roles is also a salient issue. All these proprietors discussed the different ways in which customers would approach them, according to their a priori constructions of gendered roles. For instance, where the business was run by a copreneurial couple, it was often the case that the customers would direct to the female proprietor queries concerning 
the cleanliness of the rooms and requests for blankets, irons, toiletries or food items for children. The male proprietors were more likely to be approached in relation to queries about vehicle parking and acquiring additional keys to the property. Female sole proprietors would attempt to shield their spouses from the intrusion of customers by dealing with all forms of query and emphasizing this to customers. On the other hand, the spouses of male sole proprietors were more likely to be approached by customers with business-related concerns. Male sole proprietors conceded that they did not make the effort to communicate these boundaries to customers. This is further evidence of the way in which male hosts with wives working outside the home do not protect them from the intrusions of the business and its customers in the same way as do female sole proprietors. Therefore, the gendered roles defined by the customer tend to be further reinforced by the proprietors in their reactions to them.

\section{Gender-based identities, stereotypes and coping strategies}

All the categories of proprietor participating in the research held gender-based stereotypes of their occupational group. The male participants were more likely to emphasise that the business was a serious occupation, as opposed to a hobby, and explicitly rejected, in their own cases, those female stereotypes that they perceived to be associated with running a home-based enterprise, as shown by the this excerpt:

'They're assuming that everyone has just been a housewife or something like that ... Well, I'm not just a housewife! ... I run a business' (male, sole proprietor).

Men referred to the issue of gender to a greater extent than did women, as they appeared more ambivalent about the feminized tasks they performed. The men, particularly the two defining themselves as sole proprietors, were disparaging about what they regarded as negative female traits in running the business. They distanced themselves from the labels attached to this female-dominated occupation. However, in doing so, they actively reinforced gender-based stereotypes:

I know people, women especially, who sit down and watch all this morning television. Then the doorbell goes in the afternoon and they haven't got a thing done.... Whereas my wee bit of business sense will maybe pull me through. I 
think some of them would just, you know, throw their pinnies [aprons] off and give up. (Man, sole proprietor)

The female participants also acknowledged the predominance of women in these enterprises and tended to view male sole proprietors as unusual. Proprietors of similar businesses were more likely to be portrayed as distinctive 'others' where there was disparity in terms of gender. Therefore, the women tended to empathise with other women running similar businesses and saw them as making enterprising use of their ties to family and the domestic domain:

It's usually women. There is the odd one where the man runs it and their wives go out to work, which is strange, but maybe because the wives have a good job and they make more money. Yeah. But its mostly, you know, the women who do it ... well, you're at home anyway for the kids and you don't have to go out to work. It's convenient. (Woman, sole proprietor)

You do come across the odd place run by the husband but that's more the exception. Perhaps it's because they were unable to work for some reason. Anyway, I don't think it's a thing a man would think of on his own. Maybe they go along with their wife if they're a retired couple like my husband and I. So you do it together because you're both at home. But as I was saying, it's traditionally a thing the wife did to keep her hand in while staying at home with the kids, because that can drive you crazy. You do need some adult company or you'd go mad. I think it just fits in. It just makes sense, really, for many women. (Woman, copreneur)

On the other hand, men running businesses as either sole proprietors or as part of male-only couples (the latter were not found amongst research participants), were viewed as oddities, unless they were part of a heterosexual couple and were actively aided by a female spouse. Most women saw the idea of men undertaking what were regarded as female roles, such as cleaning and bed-making, as difficult to accept. Such tasks were regarded as traditionally within their own remit and more akin to the feminized chores performed in the private home domain. This is exemplified by a 
female host's comment when discussing a man who ran a similar business to her own from his private home:

He'll need help! I just can't see a man making a bed or cleaning a shower [laughs]. He'll get a shock! Maybe he's got a romantic kind of view of it. (Woman, sole proprietor)

Both male sole proprietors and male copreneurs attempted to elevate their occupational status by distancing themselves from female sole proprietors, and by choosing to undertake activities such as household repairs and gardening. These activities were viewed as comparatively more creative and less menial and thus more masculine, than cleaning and bed-making which were seen as more feminine chores. 11 proprietors (two male sole proprietors, six female sole proprietors and three copreneurs) said that they employed the limited assistance of a cleaner on an informal basis. An interesting feature was that where female sole proprietors had paid help, this was limited to a few mornings per week. However, both male sole proprietors had more extensive paid help, thereby largely alleviating their need to undertake less desirable household tasks, such as cleaning and laundry. The cleaner was a woman in all cases of reported non-kinship help.

These results concur with the findings of writers such as Cross and Bagilhole (2002) and Simpson (2004), who examine the strategies adopted by men working in predominantly female occupations. Men tend to maintain notions of traditional masculinity by distancing themselves from female colleagues or feminized working practices, and re-labelling or elevating their own roles. In addition, the inherently feminized nature of home-based hospitality work places strains upon the gender identities of male sole proprietors, thus necessitating their use of such coping mechanisms. This was found by Alvesson (1998) in his examination of how gender relations and identity were constructed in an advertising firm, where strongly gendered positions may be seen as men's responses to the identity problems of work that has ambiguously gendered content. In the context of the present study this is further compounded by the reactions and views of female proprietors which reinforce traditional gendered stereotypes. 


\section{Discussion and conclusion}

Male and female hosts in this study are conservative in their views on gender roles in their occupational setting. This may relate to the profile of proprietors interviewed; heterosexual, self-employed, Scottish/British homeowners, aged between 40 and 69 . Although this study specifically involved home-based businesses, the findings support arguments relating to the survival of gendered ideologies concerning the division of labour in the household and the marginalization of women's place therein (Hochschild, 1990; Leonard, 2001). The findings show that gendered roles are still dominant in commercial hospitality home enterprises, regardless of whether they are operated by men, women or copreneurial couples.

The research reveals three broad proprietor categories. The first, the female sole proprietors, run their businesses on their own although they are often married. Typically, their spouses are involved in salaried employment outside the home and do not participate significantly in commercial home activities. Female sole proprietors do not expect their working spouses to assist in the running of the home enterprises and use strategies to minimize the intrusion of the business sphere into that of the home. Copreneurial couples, the second category, engage in running the home-based hospitality enterprise as a unit, but tend to do so according to traditional gender-based roles mirroring those found in the private home. The third category comprises the male sole proprietors with spouses engaged in employment outside the home. These men are generally conservative in terms of their assignment of traditional roles and do not attempt to shield their wives from the intrusive nature of their businesses. This highlights the conventional character of this occupational grouping, reinforcing existing research demonstrating that traditional, gender-based, roles are clearly apparent in small and micro business enterprises (Baines and Wheelock, 1998; Smith, 2000). It is argued that this is very pronounced in home-based commercial hospitality where home and business spheres overlap.

This research furthermore supports the view that, in this form of micro business, traditional gender divisions of labour continue to be transferred from the private home domain and extended into the business. This leads to a process whereby temporal and spatial boundaries between home and work are continuously dissolving and reforming. There can be seen to be a continuation or even reinvention of pre-modern labour processes with overlapping home-work spheres (Baines and Wheelock, 1998), despite attempts by proprietors to separate them. However, arguments around agency 
and action support findings relating to women's complicity in orchestrating and reinforcing gender-laden attitudes. This complicity serves to elevate the business status and type of participation of the man in the home-based hospitality enterprise above the level of their female counterparts.

Men may be restricted or uncomfortable in their enactment of masculinities in the home domain due to the dominant constructions of masculinity that this space traditionally allows (Whitehead, 2002). The visibility of the few male sole proprietors embracing this occupation may initially appear to indicate a change in the traditionally gendered constructions of this role as essentially feminized. However, the enlightened 'new man' was not encountered in this research. Although outward role appearances may appear similar for both male and female proprietors, role interpretations clearly differ.

Gender-based stereotypes featured strongly in interview accounts. Male proprietors, particularly those running the hospitality enterprise as a sole venture, went into great detail about the seriousness of their occupation, resenting being compared to female proprietors whom they regarded as engaging in a mere hobby. Male proprietors tended to emphasize the business domain, frequently citing customer numbers, property price increases and their business skills. They explicitly rejected those female stereotypes associated with running home-based commercial enterprises, disparaging what are seen as negative female traits if and when these were applied to them. They use this as a mechanism to distance themselves from labels attached to female-dominated roles. However, in doing so, male proprietors actively reinforce gender-based stereotypes. Female proprietors also use these labels, viewing men who run businesses from home as unusual and often questioned their ability to cope with housework and other domestic-related chores while placing great emphasis on the benefits of such work in providing the flexibility to combine income generation with domestic or family responsibilities.

From the standpoint of the hosts, the technique of distancing the self from common role stereotypes is used as a means of defining their own self-identity and status. Thus, male hosts in particular are strategic in their 'cool alternation' (Berger and Luckman, 1966), insisting upon their own views of themselves. However, the role that they play carries with it a priori associations for the holder, such as those connected with a feminized and arguably more subservient status. In the case of the 
commercial home the hosts' ideal self-projections are trapped in the broader gendered definitions of their occupational role.

Due to the overlapping nature of the business sphere, with a domestic sphere generally reserved for sole use by proprietor and family, descriptions of the business were infused with those of the related domestic context. Both men and women adopted essentially conservative viewpoints illustrating that boundaries exist between the home and the business, even where the business and home are not completely physically detached. These boundaries are continuously created, shifted and reinforced by the proprietors. The dynamic and inherently complex interplay between the business and home spheres illustrates the potentiality for tensions between work and home priorities (Wilson and Greenhill, 2004).

The persistence of traditionally gendered identity and role constructions in this occupational grouping is thus manifested by the spatial and temporal processes of organizing by the protagonists within this home-work setting. As has been shown, these mechanisms clearly differ according to the gender of the proprietor, and serve to prop up and engrain the binary divide within both tasks and expressions that are accorded either a more masculine or feminine status. This allows stereotypes and conventional dichotomies to persist despite the opportunities afforded by the overlap of the domestic setting and the potential for fluidity between spaces to overlay more malleable definitions and identities onto its occupants.

However, it is perhaps the very fact that the business is part of the home setting which causes greater resistance to less conventional gendered constructions, which may threaten the pre-existing notions such individuals attach to their home and their sense of security about their place within it. These businesses are inherently and unavoidably bound to the domestic context. As such, identity and role constructions are infused with notions of masculinity and femininity that, while appearing conservative and unchanging, yield a fragility reflected in the reassertion of traditional stereotypes and a resistance to unconventionality. This article has presented findings that delve into the particular subjectivities of these individuals and their gendered constructions. As Knights and Kerfoot (2004, p. 432) argue, 'deconstructing binary thinking and the hierarchical relations that it reflects and reproduces is unlikely to occur in the absence of changing subjectivity'.

This research advocates that increased attention be paid to gendered identity constructions, interactions and dynamics inherent in such home-based micro 
businesses. The focus on home-based hospitality businesses straddles the domains of home and work, the separation of which, seen as a feature of industrialization, is not always realized. The micro hospitality enterprise demonstrates the survival of an essentially pre-modern, conservatively organized, domestic economic activity. Home hosts are not the underpaid marginalized individuals typically found among the more menial ranks of service sector workers. They are commercial homeowners who exercise choice and control in their chosen occupation, but who still must negotiate the demands of routine domestic labour in the provision of paid service to others.

Domestic hospitality enterprises are not a new phenomenon. Yet it can be argued that such forms of domestic-based labour, although they embody conservative values and practices, are also manifestations of enhanced employment flexibility for both men and women in contemporary society (Felstead and Jewson, 2000; Felstead et al. 2005). This may be particularly relevant as home ownership has in recent decades become widespread in Scotland, as in the rest of the UK, thus providing opportunities for converting homes as fixed assets into businesses as a form of income generation. This form of non-standard autonomous employment can allow the realization of pre-modern, flexible, home-work ideals and practices. It is argued that homes providing commercial hospitality can be regarded as traditional in gender stereotype, although at the same time still distinct, as part of wider, more diverse, forms of present-day employment. In this context, forms of work are becoming increasingly dynamic so that traditional conceptions of gender may become blurred, contested, or reinforced, thus triggering complex and fluctuating gender dynamics (Alvesson, 1998).

Although these findings extend the extant knowledge base on the importance of gender in the construction of occupational identity and role configuration in homebased enterprises, certain limitations of the research must be taken into account. The research is necessarily context-bound by the socio-geographic setting of Scotland and the overall socio-demographics of the research participants. This leaves space for future research to explore other settings where individuals running similar businesses may manifest different profiles in terms of gender composition, age, sexuality and ethnicity. This would show whether the gender conservativism found in this research is apparent in contexts where the proprietor profiles may be more varied.

This research has explored the case of the owner occupied hospitality business operating very much at the micro end of the small firm spectrum. By highlighting this 
particular example of home-based enterprise, the intention is to encourage further engagement by social scientists with such forms of labour organization. Further research is needed on occupational groups such as this where evidence is scarce, due in part to the difficulties in researching such businesses as a result of their size and scale of operation, and the lack of compulsory regulation of the sector. This research has provided insights into the lived realities of the research participants that goes some way towards unearthing the nature of their gendered roles and identities.

\section{Notes}

1. In 2003, 23 per cent of the UK's 1.4 million tourist accommodation bed-spaces were in guesthouses and bed and breakfasts (StarUK, 2005).

\section{Acknowledgements}

The author is indebted to all of the individuals who took part in interviews. The fieldwork was supported by a research grant from the Carnegie Trust for the Universities of Scotland. Thanks also go to the anonymous reviewers for their helpful feedback. 


\section{References}

Adib, A. and Guerrier, Y. (2003) The interlocking of gender with nationality, race, ethnicity and class: the narratives of women in hotel work, Gender, Work \& Organization, 10,4, 413-32.

Alvesson, M. (1998) Gender relations and identity at work: a case study of masculinities and femininities in an advertising agency, Human Relations, 51,8, 969-1005.

Arrowsmith, J. Gilman, M., Edwards, P. and Ram, M. (2003) The impact of the national minimum wage in small firms, British Journal of Industrial Relations, $41,3,435-56$.

Baines, S. and Wheelock, J. (1998) Reinventing traditional solutions: job creation, gender and the micro-business household, Work, Employment \& Society, 12,4, 579-601.

Baines, S. and Wheelock, J. (2000) Work and employment in small businesses: perpetuating and challenging gender traditions, Gender, Work \& Organization, 7,1, $45-56$.

Berger, P. and Luckmann, T. (1966) The Social Construction of Reality. Harmondsworth: Penguin.

Brown, D. and Crossman, A. (2000) Employer strategies in the face of a national minimum wage: an analysis of the hotel sector, Industrial Relations Journal, 31,3, 206-19.

Cross, S. and Bagilhole, B. (2002) Girls' jobs for the boys? Men, masculinity and non-traditional occupations, Gender, Work and Organization, 9,2, 204-26.

Darke, J. and Gurney, C. (2000) Putting up? Gender, hospitality and performance. In Lashley, C. and Morrison, A. (eds.) In Search of Hospitality: Theoretical Perspectives and Debates, pp. 77-99. Oxford: Butterworth-Heinemann.

Davidoff, L. (1995) Worlds Between: Historical Perspectives on Gender and Class. Cambridge: Polity Press.

Ehlers, T. and Main, K. (1998) Women and the false promise of micro-enterprise, Gender \& Society, 12,4, 424-40.

Felstead, A and Jewson, N. (1997) Researching a problematic concept: homeworkers in Britain, Work, Employment \& Society, 11,2, 327-46.

Felstead, A. and Jewson, N. (2000) In Work, at Home: towards an Understanding of Homeworking. London: Routledge. 
Felstead, A., Jewson, N., Phizacklea, A. and Walters, S. (2001) Working at home: statistical evidence for seven key hypotheses, Work, Employment \& Society, 15,2, $215-231$.

Felstead, A., Jewson, N. and Walters, S. (2005) Changing Places of Work. Basingstoke: Palgrave Macmillan.

Giddens, A. (1979) Central Problems in Social Theory: Action, Structure, and Contradiction in Social Analysis. London: Palgrave Macmillan.

Goffman, E. (1959) The Presentation of Self in Everyday Life. London: Penguin.

Gray, M. (2004) The social construction of the service sector: institutional structures and labour market outcomes, Geoforum, 35,1, 23-34.

Guerrier, Y. and Adib, A. (2000) No, we don't provide that service: the harassment of hotel employees by customers, Work, Employment \& Society, 14,4, 689-705.

Hennon, C., Loker, S. and Walker, R. (eds) (2000) Gender and Home-Based Employment. London: Auburn House.

Hochschild, A. (1983) The Managed Heart. Berkeley, CA: University of California Press.

Hochschild, A. (1990) The Second Shift: Working Parents and the Revolution at Home. London: Piatkus.

Howe, L. (1977) Pink Collar Workers: Inside the World of Women's Work. New York: Avon.

Knights, D. and Kerfoot, D. (2004) Between representations and subjectivity: gender binaries and the politics of transformation, Gender, Work \& Organization, 11,4, $430-454$.

Leonard, M. (2001) Old wine in new bottles? Women working inside and outside the household, Women's Studies International Forum, 24,1, 67-78.

Lorber, J. (1994) Paradoxes of Gender. New Haven, CT: Yale University Press.

Lucas, R. (1995) Managing Employee Relations in the Hotel and Catering Industry. London: Cassell.

Lupton, B. (2000) Maintaining masculinity: men who do women's work, British Journal of Management, 11,3, S33-48.

Lynch, P. and MacWhannell, D. (2000) Home and commercialised hospitality. In Lasley, C. and Morrison, A. (eds) In Search of Hospitality: Theoretical Perspectives and Debates, pp. 100-17. Oxford: Butterworth-Heinemann. 
Macaulay, I. and Wood, R. (1992) Hard Cheese: a Study of Hotel and Catering Employment in Scotland. Glasgow: Scottish Low Pay Unit.

MacCannell, D. (1973) Staged authenticity: arrangements of social space in tourist settings, American Journal of Sociology, 79,3, 589-603.

Madigan R. and Munro, M. (1996) House beautiful: style and consumption in the home, Sociology, 30,1, 41-57.

Mallett, S. (2004) Understanding home: a critical review of the literature, The Sociological Review, 52,1, 62-89.

Meagher, G. (1997) Recreating 'domestic service': institutional cultures and the evolution of paid household work, Feminist Economics, 3,2, 1-27.

Moss, P. (1997) Spaces of resistance, spaces of respite: franchise housekeepers keeping house in the workplace and at home, Gender, Place and Culture, 4,2, 17996.

Oakley, A. (1974) The Sociology of Housework. Oxford: Blackwell.

Phizacklea, A. and Wolkowitz, C. (1995) Homeworking Women: Gender, Racism and Class at Work. London: Sage.

Rainsborough, J. (2002) Feminist theory — a question of difference. In Marsh, I. (ed.) Theory and Practice in Sociology, pp.257-94. Essex: Pearson.

Ritchie, J. and Spencer, L. (1994) Qualitative data analysis for applied policy research. In Bryman, A. and Burgess, R. (eds.) Analysing Qualitative Data, pp. 173-94. London: Routledge.

Rybczynski, W. (1988) Home. London: Heinemann.

Shumate, M. and Fulk, J. (2004) Boundaries and role conflict when work and family are colocated: a communication network and symbolic interaction approach, Human Relations, 57,1, 55-74.

Simpson, R. (2004) Masculinity at work: the experiences of men in female-dominated occupations, Work, Employment \& Society, 18,2, 349-68.

Simpson, R. (2005) Men in non-traditional occupations: career entry, career orientation and experience of role strain, Gender, Work \& Organization, 12,4, 363-80.

Smith, C. (2000) Managing work and family in small copreneurial business: an Australian study, Women in Management Review, 15,5-6, 283-89. 
StarUK (2005) Statistics on tourism and research: facts 3003. Available online at http://www.staruk.org.uk//default.asp?ID=587\&parentid=512<http://www.york.ac. uk/depts/hstd/centres/evidence/cebn.htm Last accessed December 2005.

Stringer, P. (1981) Hosts and guests: the bed-and-breakfast phenomenon, Annals of Tourism Research, 8,3, 357-76.

Sullivan, C. and Lewis, S. (2001) Home-based telework, gender and the synchronization of work and family: perspectives of teleworkers and their coresidents, Gender, Work \& Organization, 8,2, 123-45.

Walton, J. (1978) The Blackpool Landlady. Manchester: Manchester University Press.

Whatmore, S. (1991) Farming Women: Gender, Work and Family Enterprise. Basingstoke: Macmillan.

Whitehead, S. (2002) Men and Masculinities. Cambridge: Polity Press.

Williams, C. (1995) Still a Man's World: Men Who Do 'Women's Work'. Berkeley, CA: University of California Press.

Wilson, M. and Greenhill, A. (2004) Gender and teleworking identities in the risk society: a research agenda, New Technology, Work and Employment, 19,3, 207-21.

Wood, R. (1992) Working in Hotels and Catering. London: Routledge. 